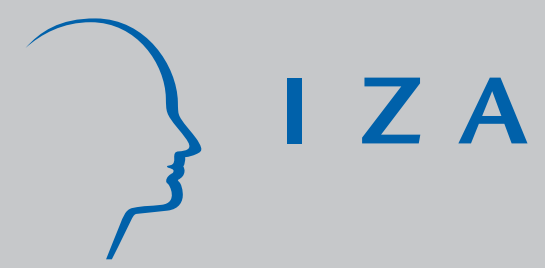

IZA DP No. 5201

Public and Private Insurance with Costly Transactions

Giuseppe Bertola

Winfried Koeniger

September 2010

Forschungsinstitut zur Zukunft der Arbeit Institute for the Study of Labor 


\title{
Public and Private Insurance with Costly Transactions
}

\author{
Giuseppe Bertola \\ Università di Torino and CEPR \\ Winfried Koeniger \\ Queen Mary University of London, \\ CEPR and IZA
}

\section{Discussion Paper No. 5201 \\ September 2010}

\author{
IZA \\ P.O. Box 7240 \\ 53072 Bonn \\ Germany \\ Phone: +49-228-3894-0 \\ Fax: +49-228-3894-180 \\ E-mail: iza@iza.org
}

\begin{abstract}
Any opinions expressed here are those of the author(s) and not those of IZA. Research published in this series may include views on policy, but the institute itself takes no institutional policy positions.

The Institute for the Study of Labor (IZA) in Bonn is a local and virtual international research center and a place of communication between science, politics and business. IZA is an independent nonprofit organization supported by Deutsche Post Foundation. The center is associated with the University of Bonn and offers a stimulating research environment through its international network, workshops and conferences, data service, project support, research visits and doctoral program. IZA engages in (i) original and internationally competitive research in all fields of labor economics, (ii) development of policy concepts, and (iii) dissemination of research results and concepts to the interested public.
\end{abstract}

IZA Discussion Papers often represent preliminary work and are circulated to encourage discussion. Citation of such a paper should account for its provisional character. A revised version may be available directly from the author. 
IZA Discussion Paper No. 5201

September 2010

\section{ABSTRACT}

\section{Public and Private Insurance with Costly Transactions}

We characterize how public insurance schemes are constrained by hidden financial transactions. When non-exclusive private insurance entails increasing unit transaction costs, public transfers are only partly offset by hidden private transactions, and can influence consumption allocation. We show that efficient transfer schemes should take into account the impact of insurance on unobservable effort and saving choices as well as the relative cost of public and private insurance technologies. We provide suggestive evidence for the empirical relevance of these results by inspecting the cross-country relationship between available indicators of insurance transaction costs and variation in public and private insurance.

JEL Classification: E21, D82, H21, G22

Keywords: $\quad$ public transfers, private insurance, moral hazard, transaction costs

Corresponding author:

Winfried Koeniger

School of Economics and Finance

Queen Mary, University of London

Mile End Road

London, E1 4NS

United Kingdom

E-mail: w.koeniger@qmul.ac.uk

\footnotetext{
* We thank colleagues and seminar participants for useful comments on earlier drafts.
} 


\section{Introduction}

This paper links insights from the classic analyses of insurance provision to the recent literature on dynamic public finance to investigate the feasibility and nature of public insurance schemes in the presence of hidden private insurance transactions. Public and private insurance provision coexist in reality, and we find that transaction costs are important both for the existence of public insurance schemes and the observed differences of public and private insurance provision across countries.

A recent literature explores the relationship between hidden actions and efficient consumption allocations. In that literature, the social efficiency of consumption allocation under uncertainty is constrained by individual agents' private interactions. The hidden-information problems studied by Mirrlees (1971), Cole and Kocherlakota (2001), and many other contributions to the "New Dynamic Public Finance" literature let income be observable and determined by effort choices based on privately observed ability realizations. In that setting, insurance contracts may be signed and public policies designed before ability levels are realized, but only non-contingent self-insurance is possible when assets are traded by agents who have private information about their own ability and exert effort privately to determine observable income.

In this paper we focus on costly insurance transactions as a reason why, in the real world, governments do implement insurance-oriented policies at the same time as private financial contracts also provide contingent payoffs. We are not the first to highlight the importance of transaction costs for hidden insurance trades. Bisin and Gottardi (1999) show that nonlinear prices of private insurance due to transaction costs are important to ensure equilibrium existence, and Gottardi and Pavoni (2009) show in a similar setting that a linear tax on hidden insurance trades is optimal. Other nonlinearitities have also been studied, for example as regards costs for private firms to monitor insurance purchases (Ales and Maziero, 2009). Our novel approach focuses on the role of explicit insurance costs in an environment where nontrivial securities can offer payoffs contingent on idiosyncratic realizations. We model price nonlinearities in terms of a smooth technology that displays decreasing returns in processing insurance transactions. This allows us to build on standard results and makes the resulting modeling environment suitable for our purpose of characterizing 
real-life public and private provision of insurance.

Section 2 sets up a modeling framework based on the hidden-action moral hazard workhorse of both classic insurance theory, such as Pauly (1974) and Shavell (1979), and of recent contributions to dynamic public finance such as Ábrahám and Pavoni (2005). In doing so, we briefly review existing characterization results on the constrained-efficient consumption allocation with hidden effort and non-contingent saving choices. Since privately chosen effort only determines the probability distribution of observable income realizations, the economy is not limited to selfinsurance. Extending the model to allow for hidden trade in state-contingent securities, Section 3 shows that price-taking behavior fails to internalize effort incentives, resulting in excessive supply of non-exclusive unit insurance contracts. Public policy is completely unable to address these incentive issues if costless competitive trade of such securities fully offsets not only random shocks, but also any public contingent transfers. Section 4 then characterizes the equilibrium and the constrained-efficient allocation if insurance transactions are costly. We show that if the underwriting cost for private insurance contracts depends nonlinearly on the amount of such transactions, public transfers cannot be fully undone by private markets. Public contingent transfers can thus affect the equilibrium allocation and improve the trade-off between consumption smoothing and effort incentives to an extent that, as we illustrate with a numerical example, depends on the size and shape of private transaction costs. In Section 5 we show that transaction costs for public and private insurance are sizeable and heterogeneous across OECD countries and briefly assess the empirical relationship between indicators for transaction and administration costs and the amounts and composition of insurance across developed countries. Section 6 concludes.

\section{Insurance and hidden actions}

When it is possible to verify the realization of relevant events but information on their probability is incomplete and asymmetric, only partial insurance is feasible. We characterize the extent and character of consumption smoothing adapting a standard two-period hidden-action problem (Ábrahám and Pavoni, 2005) which focuses on insurance of ex-ante identical individuals and allows for an analytic characterization of the consumption allocation. 
In the first period, agents derive utility $u\left(c_{1}\right)$ from consumption, with $u^{\prime}(x)>0$ and $u^{\prime \prime}(x)<0$ for all $x$. They also derive additively separable disutility $-v\left(e_{1}\right)$ from effort. We assume that $v^{\prime}(x)>0, v^{\prime \prime}(x)>0$ for $x>\underline{e}$, the lowest-effort bound, and $v^{\prime}(x)=0$ for $x \leq \underline{e}$. Effort, which is privately observed, influences the probability $f\left(z \mid e_{1}\right)$ that in the second and last period of the model income $y_{2}$ equals $z$, for each $z>0$ in the support $Y_{2}$ of income realizations. We suppose that $f\left(z \mid e_{1}\right)>0$ for all $z \in Y_{2}$ and all $e_{1}$ : this "full-support" assumption ensures that effort can never be inferred from the realization of income. And we let $f_{e}\left(z \mid e_{1}\right) \equiv \partial f\left(z \mid e_{1}\right) / \partial e_{1}$ be increasing in $z$ so that higher effort increases the mean of the income distribution since

$$
\sum_{\left\{z \in Y_{2}\right\}} f\left(z \mid e_{1}\right)=1 \Rightarrow \sum_{\left\{z \in Y_{2}\right\}} f_{e}\left(z \mid e_{1}\right)=0
$$

implies $\sum_{\left\{z \in Y_{2}\right\}} z f_{e}\left(z \mid e_{1}\right)>0$, as $f_{e}\left(z \mid e_{1}\right)$ is negative (positive) in the lower (higher) portion of the income distribution's support. The stronger, commonly-made assumption that the likelihood ratio $f_{e}\left(z \mid e_{1}\right) / f\left(z \mid e_{1}\right)$ monotonically increases in $z$ delivers the sensible and realistic implication that constrained-efficient consumption levels also are an increasing function of income realizations.

In the second and last period of the model economy, individual consumption is in general a function $c(z)$ of income realizations. If the resulting utility $u(c(z))$ is discounted by a factor $\beta$, individual maximization with respect to effort $e_{1}$ of

$$
\mathcal{U}=u\left(c_{1}\right)-v\left(e_{1}\right)+\beta \sum_{\left\{z \in Y_{2}\right\}} u(c(z)) f\left(z \mid e_{1}\right)
$$

implies the first-order condition

$$
\beta \sum_{\left\{z \in Y_{2}\right\}} u(c(z)) f_{e}\left(z \mid e_{1}\right)=v^{\prime}\left(e_{1}\right)
$$

Next, we proceed to characterize the constrained-efficient allocation in this standard hiddenaction problem. We first briefly review existing results for a problem with hidden effort and discuss how the constrained-efficient allocation changes if we also allow for hidden non-contingent savings. We then make our contribution and extend the model to hidden (costly) state-contingent insurance 
transactions.

\subsection{Hidden effort and savings}

The principal-agent problem with hidden effort can be studied using the first-order condition (3) as an incentive compatibility constraint if the likelihood ratio $f_{e}\left(z \mid e_{1}\right) / f\left(z \mid e_{1}\right)$ is monotonically increasing in $z$ and the cumulative distribution function of $z$ is convex in effort (Rogerson, 1985b). These sufficient conditions justify the so-called first-order approach to characterization of the constrained-efficient allocation of $c_{1}, e_{1}$, and $\{c(z)\}$, whereby the typical individual's welfare (2) is maximized subject to (3) and the aggregate resource constraint.

If resources can be reallocated without cost across individuals and transferred over time according to a given social rate of transformation $R=1+r$, and there are so many individuals as to let $f\left(z \mid e_{1}\right)$ represent the population fraction as well as the probability of income realizations, the relevant Lagrangian is

$$
\begin{aligned}
\mathcal{L}_{1}= & u\left(c_{1}\right)-v\left(e_{1}\right)+\beta \sum_{\left\{z \in Y_{2}\right\}} u(c(z)) f\left(z \mid e_{1}\right) \\
& +\lambda\left(y_{1}-c_{1}+\frac{1}{1+r} \sum_{\left\{z \in Y_{2}\right\}}(z-c(z)) f\left(z \mid e_{1}\right)\right) \\
& +\mu\left(\beta \sum_{\left\{z \in Y_{2}\right\}} u(c(z)) f_{e}\left(z \mid e_{1}\right)-v^{\prime}\left(e_{1}\right)\right)
\end{aligned}
$$

where $\lambda$ is the shadow price of aggregate resources as of period 1 , and $\mu$ the shadow price of the incentive compatibility constraint for effort.

Combining the conditions $\partial \mathcal{L}_{1} / \partial c(z)=0$ and $\partial \mathcal{L}_{1} / \partial c_{1}=0$ yields

$$
\left[f\left(z \mid e_{1}\right)+\mu f_{e}\left(z \mid e_{1}\right)\right] \frac{1}{u^{\prime}\left(c_{1}\right)}=\frac{1}{\beta(1+r)} \frac{f\left(z \mid e_{1}\right)}{u^{\prime}(c(z))}, \forall z \in Y_{2}
$$

a constrained-efficiency condition that would call for constant consumption and full insurance if it were the case that $f_{e}\left(z \mid e_{1}\right)=0$, which implies $\mu=0$. When instead effort affects the probability distribution of income realizations, the shadow price of the incentive constraint is positive, and (the 
marginal utility of) consumption in the second period generally depends on the income realization $y_{2} \cdot{ }^{1}$

Summing (5) over the support of second period income realizations, and recalling (1), yields a reciprocal Euler equation (Rogerson, 1985a):

$$
\frac{1}{u^{\prime}\left(c_{1}\right)}=\frac{1}{\beta(1+r)} \sum_{\left\{z \in Y_{2}\right\}} \frac{1}{u^{\prime}(c(z))} f\left(z \mid e_{1}\right) .
$$

Since $1 / x$ is a convex function, Jensen's inequality and (6) imply

$$
u^{\prime}\left(c_{1}\right)<\beta(1+r) \sum_{\left\{z \in Y_{2}\right\}} u^{\prime}(c(z)) f\left(z \mid e_{1}\right) .
$$

If it is possible to access a financial market where assets yield the social rate of intertemporal transformation $1+r$, however, it is individually optimal to satisfy the standard Euler equation

$$
u^{\prime}\left(c_{1}\right)=\beta(1+r) \sum_{\left\{z \in Y_{2}\right\}} u^{\prime}(c(z)) f\left(z \mid e_{1}\right),
$$

which is inconsistent with (6) when consumption is not constant across $z$. Since individuals benefit from shifting some of the first-period consumption to the future and from exerting less effort, efficiency is thus further constrained when savings are not observable.

When both effort and savings are chosen privately, efficiency need not in general be characterized by maximization of (2) subject to the aggregate resource constraint and the individual firstorder conditions (3) and (7), because the relevant concavity conditions may be violated. Ábrahám, Koehne and Pavoni (2009) show that the first-order approach remains valid if one imposes the sufficient conditions of a monotone likelihood ratio, a utility function with non-increasing absolute risk aversion and a log-convex probability distribution function. To characterize the constrainedefficient consumption allocation, we can then add (7) to the Lagrangian (4), with shadow price $\omega$,

\footnotetext{
${ }^{1}$ More specifically, rewriting (5) as

$$
\frac{1}{u^{\prime}(c(z))}=\left[1+\mu \frac{f_{e}\left(z \mid e_{1}\right)}{f\left(z \mid e_{1}\right)}\right] \frac{\beta(1+r)}{u^{\prime}\left(c_{1}\right)},
$$

we see that (the marginal utility of) consumption varies across income realizations if the likelihood ratio does. If $f_{e}\left(z \mid e_{1}\right) / f\left(z \mid e_{1}\right)$ increases in $z$, so does consumption.
} 
to obtain

$$
\begin{aligned}
\mathcal{L}_{2}= & u\left(c_{1}\right)-v\left(e_{1}\right)+\beta \sum_{\left\{z \in Y_{2}\right\}} u(c(z)) f\left(z \mid e_{1}\right) \\
& +\lambda\left(y_{1}-c_{1}+\frac{1}{1+r} \sum_{\left\{z \in Y_{2}\right\}}(z-c(z)) f\left(z \mid e_{1}\right)\right) \\
& +\mu\left(\beta \sum_{\left\{z \in Y_{2}\right\}} u(c(z)) f_{e}\left(z \mid e_{1}\right)-v^{\prime}\left(e_{1}\right)\right) \\
& +\omega\left(u^{\prime}\left(c_{1}\right)-\beta(1+r) \sum_{\left\{z \in Y_{2}\right\}} u^{\prime}(c(z)) f\left(z \mid e_{1}\right)\right) .
\end{aligned}
$$

Imposing that $\partial \mathcal{L}_{2} / \partial c(z)=0$ we have

$$
\beta u^{\prime}(c(z)) f\left(z \mid e_{1}\right)-\frac{\lambda}{1+r} f\left(z \mid e_{1}\right)+\mu \beta u^{\prime}(c(z)) f_{e}\left(z \mid e_{1}\right)-\omega \beta(1+r) u^{\prime \prime}(c(z)) f\left(z \mid e_{1}\right)=0,
$$

which can be rearranged to

$$
\frac{\lambda}{\beta(1+r) u^{\prime}(c(z))}=1+\mu \frac{f_{e}\left(z \mid e_{1}\right)}{f\left(z \mid e_{1}\right)}-\omega(1+r) \frac{u^{\prime \prime}(c(z))}{u^{\prime}(c(z))} .
$$

Thus, the constrained-efficient shape of $c(z)$ now depends not only on that of the likelihood ratio $f_{e}(\cdot) / f(\cdot)$, but also on that of the risk-aversion coefficient $-u^{\prime \prime}(\cdot) / u^{\prime}(\cdot)$. Since $\partial \mathcal{L}_{2} / \partial c_{1}=0$ implies that $\lambda=u^{\prime}\left(c_{1}\right)+\omega u^{\prime \prime}\left(c_{1}\right)$, we also have

$$
\left[f\left(z \mid e_{1}\right)+\mu f_{e}\left(z \mid e_{1}\right)-\omega(1+r) f\left(z \mid e_{1}\right) \frac{u^{\prime \prime}(c(z))}{u^{\prime}(c(z))}\right] \frac{1}{u^{\prime}\left(c_{1}\right)+\omega u^{\prime \prime}\left(c_{1}\right)}=\frac{1}{\beta(1+r)} \frac{f\left(z \mid e_{1}\right)}{u^{\prime}(c(z))} .
$$

Summing and using (1), the constrained-efficient allocation obeys

$$
\left[1-\omega(1+r) \sum_{\left\{z \in Y_{2}\right\}} f\left(z \mid e_{1}\right) \frac{u^{\prime \prime}(c(z))}{u^{\prime}(c(z))}\right] \frac{1}{u^{\prime}\left(c_{1}\right)+\omega u^{\prime \prime}\left(c_{1}\right)}=\frac{1}{\beta(1+r)} \sum_{\left\{z \in Y_{2}\right\}} \frac{1}{u^{\prime}(c(z))} f\left(z \mid e_{1}\right) .
$$

When agents can trade non-contingent assets in privately known amounts, the standard Euler equation is satisfied, and the expectation of reciprocal future marginal utility is not equal to the 
reciprocal of current marginal utility, as efficiency would require in (6). Indeed, hidden savings further reduce, beyond what is implied by hidden effort, the economy's ability to preserve effort incentives while decoupling consumption from income realizations.

\section{Hidden private insurance}

So far, we have illustrated existing results in the context of our model economy, where income is random for each effort level, and contingent securities may pay off upon realization of the verifiable contingencies corresponding to observable realizations of $y_{2}$. We proceed to characterize the equilibrium role of private insurance from the same constrained-efficiency perspective applied above, assuming that the realization of $y_{2}$ and any public transfers contingent on it are observable and verifiable, but realized consumption remains unobservable because individual portfolios of contingent assets are private information.

Individuals choose first-period effort $e_{1}$ and consumption $c_{1}$ as well as a portfolio of long and short positions $q(z)$ in contingent securities, so as to solve

$$
\begin{aligned}
& \max _{c_{1}, e_{1},\{q(z)\}} u\left(c_{1}\right)-v\left(e_{1}\right)+\beta \sum_{\left\{z \in Y_{2}\right\}} u(c(z)) f\left(z \mid e_{1}\right) \\
& \text { s.t. } c(z)=z+q(z)+\left(y_{1}-c_{1}\right)(1+r)-\sum_{\left\{x \in Y_{2}\right\}} q(x) p(x), \forall z,
\end{aligned}
$$

where the prices $p(z)$ of contingent securities are expressed in terms of second-period resources, and taken as given by individuals in competitive equilibrium. The price $p(z)$ of a security that entitles its purchaser to a unit of income when the purchaser's idiosyncratic realization is $y_{2}=z$, and binds its issuer to pay a unit of income when the issuer's realization is $y_{2}=z$, is independent of the individuals' identity as long as the distribution of idiosyncratic income realization is the same for all individuals. Risk-averse individuals will generally take short positions in securities that pay off upon high income realizations, long positions in those that pay off in less fortunate contingencies.

Competitive trade of such stylized securities may occur through clearing houses, or at insurance firms of indefinite size and number, that collect portfolios of assets contingent on a large number 
of different individuals' income realizations. Since all individuals are ex-ante identical, prices of such securities only depend on the income realization they refer to. As in any insurance market, however, the payoff of each security does depend on whether or not a specific individual, after issuing or purchasing the security, experiences the relevant realization. Portfolios of such securities are riskless if they are diversified across sufficiently many individuals.

\subsection{Full inefficient insurance}

When it is costless to transfer resources across individuals (and, from the point of view of each individual, across idiosyncratic income realizations), long and short transactions of realizationspecific claims $q(z)=\bar{c}_{2}-z-\left(y_{1}-c_{1}\right)(1+r)$ fully insure individuals in the competitive equilibrium at actuarially fair prices $p(z)=f\left(z \mid e_{1}\right)$. In equilibrium profits are zero and there are no arbitrage opportunities since

$$
\Sigma_{z}\left[\bar{c}_{2}-z-\left(y_{1}-c_{1}\right)(1+r)\right] p\left(z \mid e_{1}\right)=\Sigma_{z}\left[\bar{c}_{2}-z-\left(y_{1}-c_{1}\right)(1+r)\right] f\left(z \mid e_{1}\right)=0,
$$

where idiosyncratic random deviations of income realizations from their mean are zero on average.

The long and short sets of securities, which individuals are interested in buying and selling, are separated by

$$
\tilde{z}=\bar{c}_{2}=\Sigma z f\left(z \mid e_{1}\right)+\left(y_{1}-c_{1}\right)(1+r),
$$

and second-period consumption is fully smoothed

$$
u^{\prime}(c(z))=u^{\prime}\left(\bar{c}_{2}\right), \forall z .
$$

Both the usual and the reciprocal Euler equation hold at

$$
u^{\prime}\left(\Sigma z f\left(z \mid e_{1}\right)+\left(y_{1}-c_{1}\right)(1+r)\right)=\frac{u^{\prime}\left(c_{1}\right)}{\beta(1+r)}, \forall z
$$

and, by (3) and (1), the optimality condition for effort reads $v^{\prime}\left(e_{1}\right)=0$. As full insurance implies that individual consumption is unaffected by income realizations, individuals refrain from supplying 
costly effort, and set $e_{1}$ to its lowest bound $\underline{e}$.

The incentive effects of insurance, in fact, are not appropriately taken into account by nonexclusive anonymous trade of income-contingent securities. As originally pointed out by Pauly (1974), individual moral hazard is determined by total insurance, and linear pricing of insurance contracts does not incorporate their marginal impact on effort incentives.

In our model, an additional unit of state-contingent insurance affects the probability of that state's realization according to

$$
\frac{\partial f\left(z \mid e_{1}\right)}{\partial q(z)}=f_{e}\left(z \mid e_{1}\right) \frac{\partial e_{1}(\cdot)}{\partial q(z)}
$$

Recognizing that $c(z)=z+q(z)-\sum_{\left\{x \in Y_{2}\right\}} q(x) f\left(z \mid e_{1}\right)+\left(y_{1}-c_{1}\right)(1+r)$ in the first-order condition for individual effort (3), and differentiating, yields

$$
\frac{\partial e_{1}(\cdot)}{\partial q(z)}=\frac{\beta u^{\prime}(c(z)) f_{e}\left(z \mid e_{1}\right)-\beta f\left(z \mid e_{1}\right) \sum_{\left\{x \in Y_{2}\right\}} u^{\prime}(c(x)) f_{e}\left(x \mid e_{1}\right)}{v^{\prime \prime}\left(e_{1}\right)-\beta \sum_{\left\{x \in Y_{2}\right\}} u(c(x)) f_{e e}\left(x \mid e_{1}\right)} .
$$

The denominator of this expression is positive by the second-order condition for effort choice. If (14) holds, then

$$
\sum_{\left\{x \in Y_{2}\right\}} u^{\prime}(c(x)) f_{e}\left(x \mid e_{1}\right)=u^{\prime}\left(\bar{c}_{2}\right) \sum_{\left\{x \in Y_{2}\right\}} f_{e}\left(x \mid e_{1}\right)
$$

equals zero by (1), and the sign of the numerator is the same as that of $f_{e}\left(z \mid e_{1}\right)$. At the fullinsurance, minimal-effort equilibrium, effort would therefore be increased by a reduction of the positive quantity $q(z)$ of contingent securities that pay off in the lower portion of the income distribution's support, where $f_{e}\left(z \mid e_{1}\right)<0$, and by a less negative $q(z)$ in the higher portion of it, where $f_{e}\left(z \mid e_{1}\right)>0$. Since effort contributes to aggregate production, such reductions of insurance coverage are beneficial: the full insurance outcome of competitive trading of fair contracts at prices $f\left(z \mid e_{1}\right)$ is not constrained-efficient, as the flat consumption-income profile implied by (15) would fulfill the constrained optimality condition (10) under hidden savings and effort only if $f_{e}(\cdot)=0$ (to imply that $\omega=0$ and $\mu=0$, since unobservable effort and saving choices are inconsequential for efficiency).

If insurance transactions were observable, the marginal price of unit insurance contracts should include the effect represented in (16), so as to internalize the social cost of lower effort. Just like 
hidden intertemporal trade of a non-contingent bond, hidden trade of state-contingent securities reduces effort and average consumption to an extent that more than compensates the social welfare gains of smoother consumption patterns. In the economy's equilibrium with hidden savings individuals self-insure too much, as for example in Ábrahám and Pavoni (2005); and they also purchase too much insurance through hidden, linearly priced state-contingent contracts, as in Pauly (1974). Insurance contracts can internalize part of this externality by specifying prices in terms of the total, rather than marginal, quantity purchased (see also Bizer and DeMarzo, 1992). To fully correct the externality, individual risks should be exclusively covered by a single insurer. This may be possible for specific risks, such as accidents, where nonlinear pricing schedules are commonly observed in reality and information is routinely obtained about total coverage when claims are processed (Shavell, 1979). Exclusivity is much less realistic when, as in our setting, it would entail observation of the full portfolio of insurance contracts or, equivalently, of each agent's realized consumption.

Just like hidden savings imply that only suboptimal self insurance can be achieved in hiddeninformation settings, only suboptimal full insurance against random events influenced by hidden actions is possible when trade in contingent securities is frictionless. Moreover, public contingent transfers cannot influence the allocation of consumption when actuarially fair and hidden private contracts can fully offset them. If upon realization of $y_{2}=z$ an individual receives a net, possibly negative transfer $s(z)$ from a public redistribution scheme, along with the amount $q(z)$ paid off by private insurance contracts held, the contingent resource constraint in (12) is replaced by

$$
c(z)=z+q(z)+s(z)+\left(y_{1}-c_{1}\right)(1+r)-\sum_{x} q(x) p\left(x \mid e_{1}\right)
$$

where taxes and transfers net out to zero in the aggregate, $\sum_{x} s(x) f\left(x \mid e_{1}\right)=0$. Since the amount of private insurance $q(z)$ can vary so as to perfectly offset public transfers upon each income realization, so as to ensure that (14) is satisfied at the same $c(z)$ for any $s(z)$, the equilibrium allocation still stabilizes consumption fully, and fails to deliver constrained-optimal effort incentives. 


\section{Costly insurance transactions}

Since neither full insurance nor the irrelevance of public state-contingent transfers are realistic, we proceed to illustrate how plausible insurance-provision costs can change these results. We first outline below how transaction costs can imply that security prices depend nonlinearly on the total amount traded. We then characterize the equilibrium and proceed to show how public transfers can improve the efficiency of the consumption allocation.

We assume that transaction costs vanish smoothly as transactions go to zero, so that we may continue to focus on interior maximization conditions. This makes our model different, in ways that suit our purposes, from those proposed by Gottardi and Pavoni (2009), where discrete bid-ask spreads imply $q(z)=0$ corner solutions for an intermediate range of $z$ realizations, and by Bisin and Gottardi (1999), who show that allowing for bid-ask spreads ensures existence of a non-exclusive trading equilibrium in the presence of adverse-selection information problems.

We suppose that insurance transactions for each contingency are processed by firms that use decreasing-returns technologies. ${ }^{2}$ Transaction costs increase the marginal cost of delivering a unit of goods to consumers who short contingent securities, and reduce the contributions to the firm's revenues of goods delivered to the firm by consumers who hold long positions in contingent securities. We suppose that the cost of writing a contract for contingent delivery of consumption goods is unitary when the scale of operations is infinitesimally small, but more than proportionally and smoothly increasing in the total amount underwritten by each firm. Formally, denoting with $m(x(z))$ the marginal cost of writing $x(z)$ unit contracts for delivery contingent on a specific realization $z$ we assume that

$$
\begin{aligned}
m(0) & =1 \\
m^{\prime}(x) & >0, \quad m^{\prime \prime}(x)>0, \quad \forall x .
\end{aligned}
$$

Since writing more claims on specific realizations is more than proportionally expensive, it is not

\footnotetext{
${ }^{2}$ Constant returns would imply linearly priced state-contingent contracts, and increasing returns would tend to concentrate transactions, inconsistently with a competitive market structure and with the realistic non-exclusive insurance arrangements we focus on.
} 
efficient for firms to specialize in subsets of the securities' space, and idiosyncratic uncertainty cancels out in the customer base of firms that trade all contingent securities with a large number of individuals. Competitive equilibrium then features risk-neutral price-taking behavior by the insurance industry: if state $z$ occurs with probability $f\left(z \mid e_{1}\right)$ and the typical insurance firm is issuing or underwriting $x(z)$ such contracts, the price of a contract that will deliver a unit of goods upon realization of $z$ equals its expected marginal cost,

$$
p\left(z \mid e_{1}, x(z)\right)=f\left(z \mid e_{1}\right) m(x(z)) .
$$

The typical decreasing-returns firm earns profits

$$
X=\sum_{\left\{z \in Y_{2}\right\}} f\left(z \mid e_{1}\right)(m(x)-a(x)) x
$$

where

$$
\begin{aligned}
a(x) & \equiv \frac{\int_{0}^{x} m(y) d y}{x} \\
a(0) & =1, \quad a^{\prime}(x)=(m(x)-a(x)) \frac{1}{x}, \quad 0<a^{\prime}(x)<m^{\prime}(x)
\end{aligned}
$$

is the average cost function implied by the marginal cost function introduced in (17).

In what follows we characterize the implications of this technological structure letting the number of competitive firms be fixed exogenously. In Appendix I, which discusses numerical solution of the equilibrium, we mention how a finite number of firms could be determined endogenously by a zero-profit condition and firm-level set-up costs. In both cases, security-level decreasing returns imply that insurance is "smoothly" imperfect for all individuals across the whole range of possible income realizations. This differentiates our model economy from Gottardi and Pavoni (2009) where security-level bid-ask spreads imply that no insurance contracts are written for a subset of realizations, and Ales and Maziero (2009) where individual-specific costs imply that in equilibrium a subset of individuals with low average productivity is uninsured.

As we will see below, decreasing-returns supply of hidden private insurance makes it possible 
for public transfers to affect equilibrium consumption patterns. We suppose that the public tax and transfer scheme also entails realistic transaction (or administration) costs which, like those of private contracts, are defined at the level of income realizations. Denote with $b(s(z))$ the average cost of transferring $s(z)$ units of resources to individuals who experience realization $z$, or collecting $-s(z)$ if that contingency makes individuals liable to be taxed. We suppose that the average cost is nil in the absence of any such transfer, but positive when transfers are not zero and possibly, but not necessarily, smoothly increasing like the private average cost counterpart.

\subsection{Costly private insurance in competitive equilibrium}

In competitive equilibrium, the aggregate contingent-security transaction amount $\bar{q}(z)$ is taken as given by each seller and purchaser of contingent assets. We normalize the number of insurance firms to unity, so that $\bar{q}(x)=x(z)$, and consider the individual maximization problem

$$
\begin{aligned}
\max _{c_{1}, e_{1},\{q(z)\}} & u\left(c_{1}\right)-v\left(e_{1}\right)+\beta \sum_{\left\{z \in Y_{2}\right\}} u(c(z)) f\left(z \mid e_{1}\right) \\
\text { s.t. } & c(z)=z+q(z)+s(z)+\left(y_{1}-c_{1}\right)(1+r) \\
& -\sum_{\left\{x \in Y_{2}\right\}} q(x) f\left(x \mid e_{1}\right) m(\bar{q}(x))+X-T, \forall z,
\end{aligned}
$$

where we denote with $X$ the profits accruing to the ex-ante identical representative individual when the decreasing-returns insurance technology is active and with $T$ the lump-sum tax which finances the aggregate net cost (if any) of public taxes and transfers.

Individuals take as given insurance prices, $X$, and $T$. Their effort choice still satisfies (3), and combining the first-order conditions for $c_{1}, c(z)$ and $q(z)$ we find that for the individually optimal choice of insurance $q(z)$

$$
u^{\prime}(c(z)) \beta(1+r) f\left(z \mid e_{1}\right)=u^{\prime}\left(c_{1}\right) f\left(z \mid e_{1}\right) m(\bar{q}(z)) \quad \forall z \in Y_{2} .
$$

Summing (20) over all $z$ we see that for (20) to be consistent with the standard Euler condition (7), which also needs to hold in the presence of a non-contingent savings asset, it must be the case 
that

$$
\sum_{\left\{z \in Y_{2}\right\}} p\left(z \mid e_{1}, \bar{q}(z)\right)=\sum_{\left\{z \in Y_{2}\right\}} f\left(z \mid e_{1}\right) m(\bar{q}(z))=1 .
$$

Since non-contingent resources can be obtained by holding a fully diversified portfolio of contingent securities with non-zero expected value, deviations from actuarial fairness of contingent prices must average out across realizations, as in (21), to rule out riskless arbitrage opportunities. ${ }^{3}$

\subsection{The consumption effects of public transfers}

Conditions (20) imply that consumption insurance is incomplete: marginal utility varies across income realizations, and is higher in contingencies where agents hold larger long insurance positions, according to

$$
\frac{u^{\prime}(c(x))}{u^{\prime}(c(y))}=\frac{m(\bar{q}(x))}{m(\bar{q}(y))}, \quad \forall x, y \in Y_{2}
$$

In the absence of public transfers, the size of private insurance positions is inversely related to that of income realizations. Since the amount of security transactions influences the price and cost of private insurance, however, taxes and transfers denoted by $s(z)$ can alter both the equilibrium consumption levels $c(z)$ and the volume $q(z)$ of security transactions.

To see this formally, note that in the ex-ante symmetric equilibrium, where $\bar{q}(x)=q(x)$ for all $x \in Y_{2}$, the profits and lump-sum tax, which the individual problem (19) takes as given, amount

\footnotetext{
${ }^{3}$ Dividing by $m(\bar{q}(z))$ in $(20)$ and taking the probability-weighted sum we also find that
}

$$
u^{\prime}\left(c_{1}\right)=\beta(1+r) \sum_{\left\{z \in Y_{2}\right\}} \frac{u^{\prime}(c(z))}{m(\bar{q}(z) / N)} f\left(z \mid e_{1}\right) .
$$

This equation and (7) can be rearranged to obtain

$$
\sum_{\left\{z \in Y_{2}\right\}}\left[\frac{1}{m(\bar{q}(z) / N)}-1\right] \frac{u^{\prime}(c(z))}{u^{\prime}\left(c_{1}\right)} f\left(z \mid e_{1}\right)=0,
$$

a standard asset-pricing equation that constrains expected proportional deviations from actuarial fairness to average to zero when weighted by the pricing kernel $u^{\prime}(c(z)) / u^{\prime}\left(c_{1}\right)$, a state-specific rate of transformation which depends on the sign and size of state-contingent security transactions. 


$$
\begin{aligned}
X & =\sum_{\left\{x \in Y_{2}\right\}} f\left(x \mid e_{1}\right) q(x)[m(q(x))-a(q(x))] \\
T & =\sum_{\left\{x \in Y_{2}\right\}} f\left(x \mid e_{1}\right) s(x) b(s(x)) .
\end{aligned}
$$

In the budget constraint of problem (19), the total cost of operating private and public contingent schemes is subtracted from the typical individual's resources:

$$
-\sum_{\left\{x \in Y_{2}\right\}} q(x) f\left(x \mid e_{1}\right) m(q(x))+X-T=-\sum_{\left\{x \in Y_{2}\right\}} f\left(x \mid e_{1}\right)[q(x) a(q(x))+s(x) b(s(x))] .
$$

Defining

$$
\kappa \equiv\left(y_{1}-c_{1}\right)(1+r)-\sum_{\left\{x \in Y_{2}\right\}} f\left(x \mid e_{1}\right)[q(x) a(q(x))+s(x) b(s(x))]
$$

and using $c(z)=z+q(z)+s(z)+\kappa$ in the individual's first-order condition for insurance transactions (20), where $\bar{q}(z)=q(z)$ as in ex-ante symmetric equilibrium per-capita averages are equal to individual choice variables, we have

$$
u^{\prime}(c(z))=\frac{u^{\prime}\left(c_{1}\right)}{\beta(1+r)} m(c(z)-z-s(z)-\kappa)
$$

Differentiating this condition with respect to $s(z)$ yields

$$
\begin{aligned}
u^{\prime \prime}(c(z)) \frac{\partial c(z)}{\partial s(z)}= & \frac{u^{\prime}\left(c_{1}\right)}{\beta(1+r)} m^{\prime}(q(z))\left(\frac{\partial c(z)}{\partial s(z)}-1-\frac{\partial \kappa}{\partial s(z)}\right) \\
& +\frac{\partial u^{\prime}\left(c_{1}\right)}{\partial s(z)} \frac{1}{\beta(1+r)} m(q(z))
\end{aligned}
$$

and shows that public transfers can influence security portfolios and consumption patterns when the costs of private insurance transactions are increasing. Rearranging,

$$
\frac{\partial c(z)}{\partial s(z)}=\frac{m^{\prime}(q(z))}{m^{\prime}(q(z))-\frac{u^{\prime \prime}(c(z))}{u^{\prime}\left(c_{1}\right)} \beta(1+r)}\left(1+\frac{\partial \kappa}{\partial s(z)}\right)-\frac{\frac{\partial u^{\prime}\left(c_{1}\right)}{\partial s(z)}}{u^{\prime}\left(c_{1}\right)} \frac{m(q(z))}{m^{\prime}(q(z))-\frac{u^{\prime \prime}(c(z))}{u^{\prime}\left(c_{1}\right)} \beta(1+r)}
$$


The first fraction indexes the extent of pass-through of the transfer to contingent consumption, and ranges between zero (to imply full crowding out by offsetting insurance positions) if $m^{\prime}(\cdot)=0$, and unity (no crowding out) if $m^{\prime}(q(z))$ is very large, or the agent is nearly risk neutral in the second period. It multiplies the transfer's unitary impact on contingent resources, plus the change in the common term $\kappa$, defined in (23), of all second-period consumption levels. The second part of expression (25) captures the impact on insurance costs of changes in the first-period marginal utility on the right-hand side of equation (20). This would be the only effect if $m^{\prime}(q(z))=0$, in which case public transfers would affect second-period consumption levels only through the net costs (if any) captured by the lump-sum tax $T$.

\subsection{Constrained efficiency}

If contingent prices include nonlinear transaction costs, private contracts only partially smooth the differences across realizations of disposable income, $z+s(z)$. Hence, they cannot fully offset public transfers which, therefore, affect the contingent profile of consumption as well as, through ex-ante effort provision incentives and insurance costs, its overall level.

Since the economy's competitive equilibrium is not constrained efficient in the presence of the informational externalities discussed above, transfers not only can, but should affect consumption patterns and effort choices. To characterize the constrained-efficient allocation we set up the Lagrangian

$$
\begin{aligned}
\mathcal{L}_{3}= & u\left(c_{1}\right)-v\left(e_{1}\right)+\beta \sum_{\left\{x \in Y_{2}\right\}} u(c(x)) f\left(x \mid e_{1}\right) \\
& +\lambda\left(y_{1}-c_{1}+\frac{1}{1+r} \sum_{\left\{x \in Y_{2}\right\}} f\left(x \mid e_{1}\right)\{x-c(x)+q(x)+s(x)-[q(x) a(q(x))+s(x) b(s(x))]\}\right) \\
& +\mu\left(\beta \sum_{\left\{x \in Y_{2}\right\}} u(c(x)) f_{e}\left(x \mid e_{1}\right)-v^{\prime}\left(e_{1}\right)\right) \\
& +\omega\left(u^{\prime}\left(c_{1}\right)-\beta(1+r) \sum_{\left\{x \in Y_{2}\right\}} u^{\prime}(c(x)) f\left(x \mid e_{1}\right)\right) \\
& +\sum_{\left\{x \in Y_{2}\right\}} \varphi(x)\left(u^{\prime}\left(c_{1}\right)-\beta(1+r) \frac{1}{m(q(x))} u^{\prime}(c(x))\right) .
\end{aligned}
$$


Unlike problems $\mathcal{L}_{1}$ in (4) and $\mathcal{L}_{2}$ in (8), problem $\mathcal{L}_{3}$ in (26) includes in the last line a summation of terms that have to be zero if the private insurance first-order conditions (12) are satisfied, and are multiplied by shadow prices $\varphi(x)$. These multipliers represent the welfare effects of the incentive-compatibility conditions for hidden insurance transactions: $\varphi(x)>0$ for securities that individuals find optimal to hold in their portfolios (because they pay off in high-marginal-utility contingencies), and $\varphi(x)<0$ for securities that individuals choose to sell short (so that they will pay, rather than receive, units of consumption when their income is realized at $x$ ).

The contingent-transfer schedule $s(z)$ is known to individuals in equilibrium. Given the set of disposable incomes $\{z+s(z)\}$, problem (26) accounts for incentive compatibility which requires that the hidden choices of effort $e_{1}$, consumption $c_{1}$, and insurance $q(z)$ satisfy the first-order conditions of the individual's maximization problem. ${ }^{4}$ The constrained-efficient allocation implemented by the set of transfers $\{s(z)\}$ implies that the derivatives of the Lagrangean with respect to these choice variables are zero, thus ensuring that a marginal change in the allocation is not welfare-improving.

In our modeling framework, the agent hiddenly chooses state-contingent securities. This makes it more difficult for the principal to implement the constrained efficient allocation, in ways that can be characterized by inspection of the condition $\partial \mathcal{L}_{3} / \partial q(z)=0$, which takes into account the effect of effort and insurance choices on the insurance price $f\left(z \mid e_{1}\right) m(q(z)$. In order to derive this condition note that the consumption level $c(x)$ is related to the insurance quantity $q(x)$ by $c(x)=x+q(x)+s(x)+\kappa$ where $\kappa$, as defined in (23), incorporates the economy-wide resource constraint, and depends on the total quantity and cost of insurance. Hence,

$$
\begin{aligned}
\frac{\partial c(x)}{\partial q(z)} & =1_{[x=z]}-\frac{\partial \kappa}{\partial q(z)} \\
& =1_{[x=z]}-f\left(z \mid e_{1}\right) m(q(z)),
\end{aligned}
$$

\footnotetext{
${ }^{4}$ The first-order conditions characterize the optimum only if the Hessian of the objective function is negative semi-definite. The conditions in Ábrahám, Koehne and Pavoni (2009) are sufficient if private security trading is prohibitively costly, so that incentive compatibility matters only for hidden effort and non-contingent savings. As in simpler settings with hidden effort and hidden savings, little can be said analytically about the constrainedefficient consumption allocation if we do not assume the validity of the first-order approach. Below we provide a plausible numerical example in which we check the properties of the Hessian to ensure that the first-order approach is appropriate.
} 
where the second equality recognizes that $\partial[q(z) a(q(z))] / \partial q(z)=m(q(z))$ in the partial derivative of the expression defined in $(23)$ and $1_{[x=z]}$ is an indicator function which is 1 if $x=z$ and 0 otherwise.

Using the budget constraint to substitute $c(x)$, the aggregate resource constraint in $(26)$ is redundant, and $\partial \mathcal{L}_{3} / \partial q(z)=0$ implies

$$
\begin{aligned}
& \beta \sum_{\left\{x \in Y_{2}\right\}} u^{\prime}(c(x))\left[1_{[x=z]}-f\left(z \mid e_{1}\right) m(q(z))\right] f\left(x \mid e_{1}\right) \\
& +\mu \beta \sum_{\left\{x \in Y_{2}\right\}} u^{\prime}(c(x))\left[1_{[x=z]}-f\left(z \mid e_{1}\right) m(q(z))\right] f_{e}\left(x \mid e_{1}\right) \\
& -\omega \beta(1+r) \sum_{\left\{x \in Y_{2}\right\}} u^{\prime \prime}(c(x))\left[1_{[x=z]}-f\left(z \mid e_{1}\right) m(q(z))\right] f\left(x \mid e_{1}\right) \\
& -\sum_{\left\{x \in Y_{2}\right\}} \varphi(x) \beta(1+r) \frac{1}{m(q(x))} u^{\prime \prime}(c(x))\left[1_{[x=z]}-f\left(z \mid e_{1}\right) m(q(z))\right] \\
& \quad+\varphi(z) \beta(1+r) \frac{m^{\prime}(q(z))}{m(q(z))^{2}} u^{\prime}(c(z)) \\
& =0 .
\end{aligned}
$$

Collecting terms that measure the ex-ante welfare impact of the insurance transaction's marginal cost - directly and in terms of shadow-price weighted derivatives of the incentive compatibility constraints- and defining the shadow value of resources in terms of the second period

$$
\begin{aligned}
\xi \equiv & \sum_{\left\{x \in Y_{2}\right\}} u^{\prime}(c(x)) f\left(x \mid e_{1}\right)+\mu \sum_{\left\{x \in Y_{2}\right\}} u^{\prime}(c(x)) f_{e}\left(x \mid e_{1}\right) \\
& -(1+r) \omega \sum_{\left\{x \in Y_{2}\right\}} u^{\prime \prime}(c(x)) f\left(x \mid e_{1}\right)-(1+r) \sum_{\left\{x \in Y_{2}\right\}} \frac{\varphi(x)}{m(q(x))} u^{\prime \prime}(c(x)),
\end{aligned}
$$

the constrained-efficiency condition (27) can be rearranged to

$$
\begin{aligned}
\frac{m(q(z))}{u^{\prime}(c(z))} \xi= & 1+\mu \frac{f_{e}\left(z \mid e_{1}\right)}{f\left(z \mid e_{1}\right)}-\omega(1+r) \frac{u^{\prime \prime}(c(z))}{u^{\prime}(c(z))} \\
& -\varphi(z) \frac{1+r}{f\left(z \mid e_{1}\right) m(q(z))}\left(\frac{u^{\prime \prime}(c(z))}{u^{\prime}(c(z))}-\frac{m^{\prime}(q(z))}{m(q(z))}\right) .
\end{aligned}
$$

Since $\xi=\lambda /[\beta(1+r)]$, this expression coincides with its familiar counterpart (9) in the absence 
of hidden costly insurance transactions with $\varphi(z)=0$ and $m(0)=1$. Hidden and costly insurance transactions influence the relationship between income realizations and (marginal utilities of) consumption levels in the second period, in two conceptually distinct ways.

On the left-hand side of $(28)$ the marginal cost $m(q(z)) \neq 1$ of additional contingent consumption is higher when income realizations imply relatively high marginal utility. Quite intuitively, the higher cost of transferring resources across different income realizations reduces the scope of insurance from the social point of view, as well as from the individual one highlighted by expression $(22)$.

Moreover, the new term in the second line on the right-hand side of (28) captures the way in which the additional incentive constraints for hidden insurance purchases exacerbate moral hazard. The severity of the incentive problem is measured by the shadow prices $\varphi(z)$, which are positive for securities that pay off in low income states, and negative for securities shorted by individuals. The implications for the constrained-efficient pattern of contingent marginal utilities depend on the difference between the local concavity of utility and convexity of insurance transaction costs, $u^{\prime \prime}(c(z)) / u^{\prime}(c(z))-m^{\prime}(q(z)) / m(q(z))$. Since this term is unambiguously negative, the incentive constraints imposed by hidden insurance transactions imply smoother consumption. In low income states, for example, the efficient marginal utility of consumption is lower, for a given pattern of insurance costs $m(q(z))$.

\subsection{Numerical illustration}

Hidden costly insurance transactions imply that public transfers $\{s(z)\}$ can influence the statecontingent consumption directly, and also indirectly through their implications for incentives and insurance choices. The interplay of these channels has intuitive but complex implications for welfare optimization. On the one hand, substitution of costly private contracts with public transfers may reduce the overall cost of insurance, depending on the relationship between private transaction costs and public administration costs. On the other hand, competitive private markets neglect effort incentives, and this makes it socially optimal to reduce insurance instead of making it less expensive.

To further illustrate the model's main implications of interest, we proceed to discuss a simple 


\begin{tabular}{ccc}
\hline \hline & \multicolumn{2}{l}{ Parameters } \\
\hline Preferences & $\beta$ & 0.96 \\
$u\left(c_{t}\right)=\frac{c_{t}^{1-\sigma}-1}{1-\sigma}$ & $\sigma$ & 2 \\
$v\left(e_{1}\right)=\frac{1}{\kappa} e_{1}^{\kappa}$ & $\kappa$ & 2 \\
\hline Technology & $r$ & 0.04 \\
$f\left(z_{1} \mid e_{1}\right)=\exp \left(-\xi e_{1}\right)$ & $\xi$ & 1 \\
$m(\bar{q}(z))=\exp (\nu \bar{q}(z))$ & $\nu$ & {$[25,50,75]$} \\
\hline Incomes & $y_{1}$ & 1 \\
& $z_{1}$ & 0.65 \\
& $z_{2}$ & 1.9 \\
\hline \hline
\end{tabular}

Table 1: Parameters for the numerical example

numerical example with two income states $z_{1}$ and $z_{2}$. The steps for the numerical solution are described in Appendix I. Table 1 displays the chosen parameters. We use a quadratic disutility of effort and an exponential functional form for the probability $f\left(z_{1} \mid e_{1}\right)=\exp \left(-\xi e_{1}\right)$ so that $f\left(z_{2} \mid e_{1}\right)=1-\exp \left(-\xi e_{1}\right)$. This functional form implies log-convexity of the distribution function and monotonicity of the likelihood ratio. We use a constant relative risk aversion utility function, which fulfills the sufficient conditions for the validity of the first-order approach with hidden effort and savings in Ábrahám, Koehne and Pavoni (2009). Since these conditions are no longer sufficient with hidden insurance, we check the concavity of the problem in our numerical example by verifying that the eigenvalues of the Hessian at the computed equilibrium are negative.

Two sets of parameters deserve further explanation. We solve the numerical example for three different values of $\nu$ to illustrate the effect of different slopes for the transaction costs. To give an example what the values of $\nu$ mean for the prices of insurance transactions, $\nu=25$ implies an empirically plausible load of $28 \%$ for a contract that increases income by 0.01 . The specified incomes $z_{1}$ and $z_{2}$ imply that the expected income in the second period is between $3 \%$ and $13 \%$ higher than in the first period, depending on the income compression with public transfers and the corresponding changes in effort.

Figures 1 and 2 display the results. In Figure 1 we plot the equilibrium variables for differently compressed income in the second period. Along the horizontal axis, the figure measures the amount $x$ of resources transferred from the high-income to the low-income contingency. The re- 
sulting income compression reduces private insurance transactions, but does not eliminate private insurance completely over the $0 \leq x \leq 0.2$ range considered in Figure 1 . It also reduces the extent to which consumption responds to income realizations, and therefore decreases equilibrium effort and (precautionary) savings. As illustrated in the figure, the equilibrium also depends on the slope of transaction costs $\nu$ : when unit transaction costs are more steeply increasing, insurance is more limited and effort is higher.

Public contingent transfers improve welfare through reduction of consumption volatility and of costly private insurance, worsen welfare through reduction of effort incentives, and may of course entail transaction and administration costs of their own. To summarize the interplay of these factors, we compute numerically the second-period lump-sum tax that would equalize welfare across the equilibria with and without a public insurance scheme resulting in income compression: if the (unspecified) administration costs of the public redistribution scheme are smaller, then the scheme is socially beneficial.

The left panel of Figure 2 plots, for different values of the critical parameter $\nu$, the ratio of the lump-sum-equivalent welfare gain to the amount of implemented income compression. We see that, for example, if $\nu=25$ then income compression by $x=0.1$ improves welfare as long as its administration absorbs less than three quarters of the amount transferred from good to bad realizations. This critical cost ratio falls if income is more compressed, indicating that further income compression becomes less attractive.

Specifying a cost for public transactions then makes it possible to determine the optimal size of the public redistribution policy. The size and shape of private transaction costs play an important role from that perspective. A larger $\nu$ shifts the curve upwards, and makes public insurance more attractive for any specification of its cost: public insurance has more positive welfare implications when hidden private transactions face steeply increasing costs and can implement only shallow and very costly consumption smoothing. 

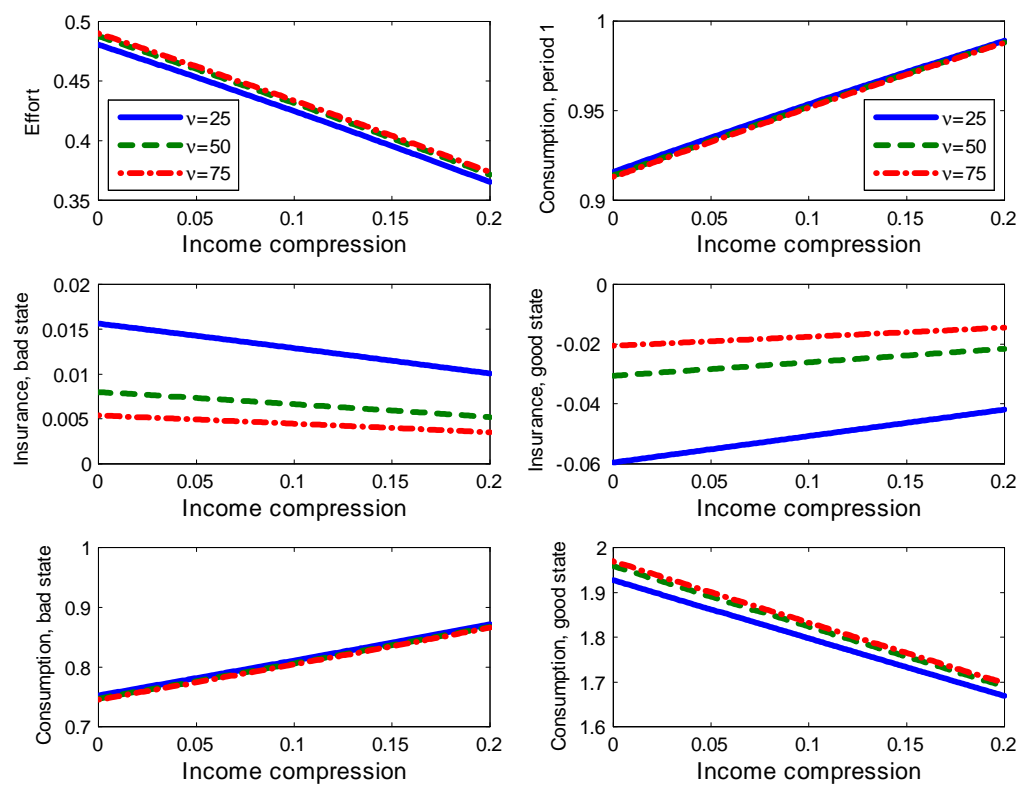

Figure 1: The equilibrium as a function of second-period income compression for different privateinsurance transaction cost parameters.
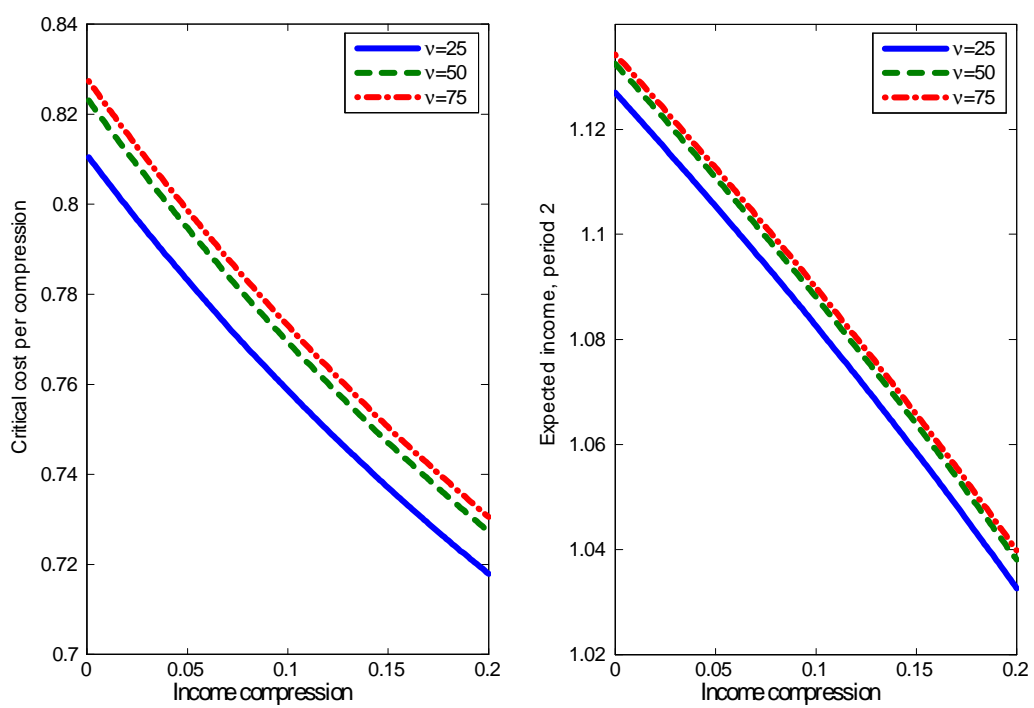

Figure 2: The welfare effect of public insurance, gross of implementation costs, in lump-sum equivalent terms. 


\section{$5 \quad$ A look at the facts}

The model quite intuitively predicts that private insurance should be less developed when transaction costs are more strongly increasing; that public insurance is more intense when incentive constraints are less binding, risk aversion is stronger and public insurance is less costly; but also that there is scope for public transfers only when private insurance is costly. These and other features may explain the variation across countries of private and public insurance.

We focus on transaction and administration costs as an essential element of realistically imperfect insurance systems, and explore the extent to which they can ceteris paribus explain crosscountry evidence. Although the available data heavily constrain the empirical analysis, the data show that transaction costs are sizeable and important, supporting the relevance of our modeling perspective.

We measure differences in public and private insurance provision across countries using data on private insurance claims from the OECD Insurance Statistics Yearbook and data on public social expenditures from the OECD Social Expenditure Database. To focus on public and private insurance against labor market and health shocks, we use the amount of non-life private insurance claims for private insurance and exclude pensions in the public-insurance data. Comparable data are available for the 1996-2005 decade. Since the time-series variation in the private-insurance data is rather noisy, we summarize its cross-country variation with the median over that period. Further details about the data set are in Appendix II.

Figure 3 shows that no obvious pattern emerges when we plot public against private insurance. Vast differences are observed across countries in both the total amount and composition of insurance amounts. Public social insurance transfers are about 20\% of GDP in Scandinavian countries, and less than $15 \%$ of GDP in the US or Canada. Across these groups of countries private insurance expenditures appear to substitute public schemes: in the US and Canada, non-life private insurance at about 3\% of GDP is much more important than in Scandinavian countries. But other countries (such as Italy, Greece, Turkey, Japan and South Korea) have a small volume in both public and private insurance. Across the OECD sample, the correlation coefficient between public and private insurance shares of GDP is positive at 0.32 , and insignificant at the $10 \%$ level. We now relate these 


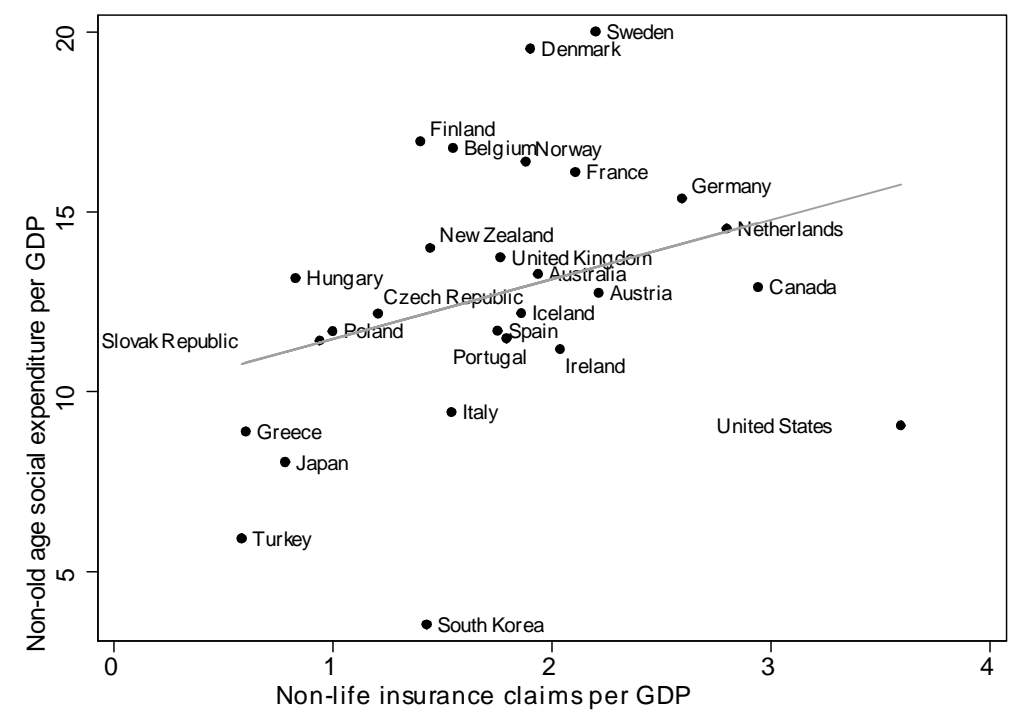

Figure 3: Public and private insurance across OECD countries. Notes: 1996-2003 and 1996-2005 averages in \% of GDP, respectively. Public insurance is measured as social expenditure per GDP other than pension and survivorship payments (source: OECD, Social Expenditure Database); private insurance is measured as claims per GDP, excluding life insurance (source: OECD, Insurance Statistics Yearbook). Solid graph: predicted values of linear regression.

measures for public and private insurance to available transaction cost indicators.

We use OECD data on administration costs per net revenue collection as our measure for transaction costs of public insurance and operating expenses per claim as our measure of transaction costs for private insurance. ${ }^{5}$ These data are far from perfect. For example, operating expenses also include acquisition/sales costs which may or may not be spread over the duration of contracts in the balance sheet of insurance firms. The data capture some of the variation we are interested in, however, and are the best data available for our purposes.

Figures 4 and 5 show that the transaction costs differ considerably across countries and are negatively related to public and private insurance transactions, consistent with our model. For example, the low public and private insurance in a Mediterranean country like Portugal is associated with relatively high administration costs of tax collection (about $2 \%$ of the revenues) and high

\footnotetext{
${ }^{5}$ Since there are no data on claims and operating expenses for the US, we use $18 \%$ as a proxy for the private transaction cost per claim in the US, suggested by the estimates of the loading factor in Brown and Finkelstein's (2007) analysis of the US long-term care market. As a proxy for US claims, we use the data on gross-written non-life insurance premiums for the US and compute claims by multiplying US premiums with the claim/premium ratio averaged across all countries for which we have data.
} 


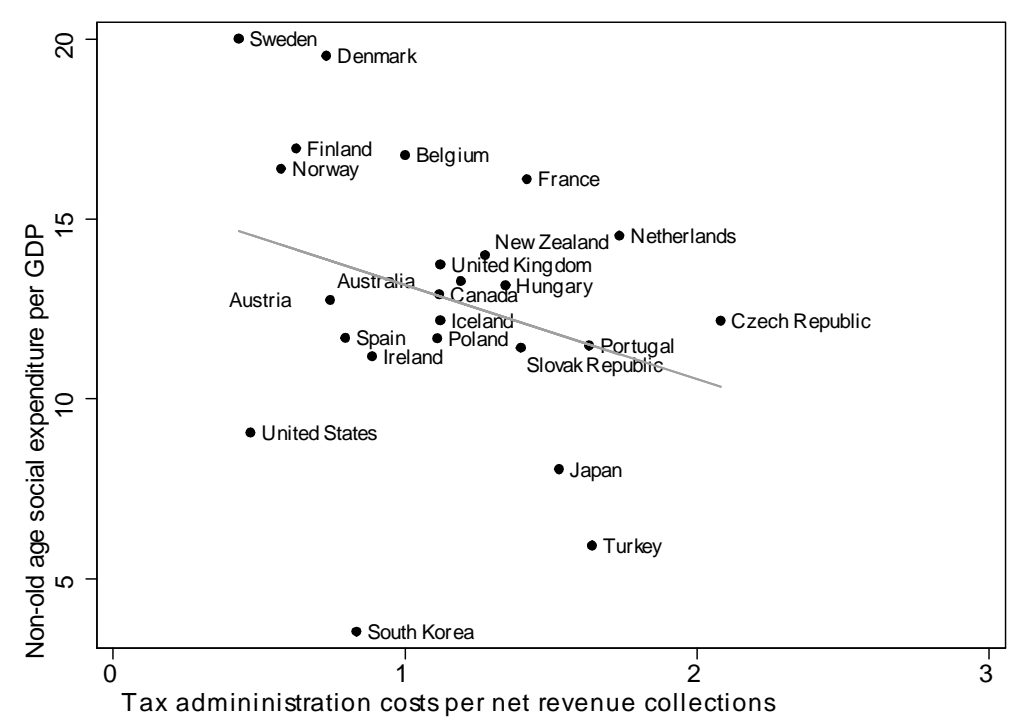

Figure 4: Public insurance and its cost in \%. Notes: Social expenditure is the average for the period 1996-2003 in the Social Expenditure Database, OECD. The tax administration cost is the average for the period 2000-2002 in OECD (2004), Table 17. Solid graph: predicted values of linear regression.

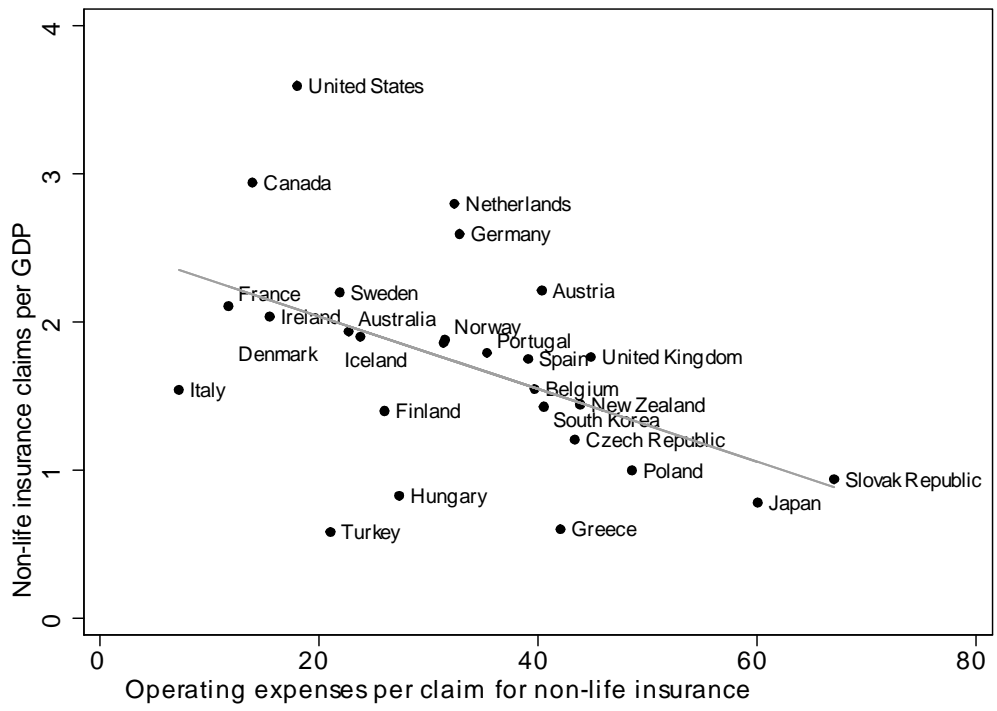

Figure 5: Private insurance and its costs in \%. Notes: Medians for the period 1996-2005. Data are from the OECD, Insurance Statistics Yearbook. Solid graph: predicted values of linear regression. 
operating expenses per claim (about $40 \%$ of claims) in the private insurance market. Scandinavian and Anglo-Saxon countries both have lower operating expenses per claim than most countries (about 20-30\%) but Scandinavian countries also have rather low public administration costs (at less than $1 \%$ of collected revenues, even lower than in Anglo-Saxon countries like Australia, Canada or the UK).

The bivariate correlation between social expenditures and administration costs in Figure 4 is -0.29 . The value becomes -0.43 and significant at the $5 \%$ level if we exclude South Korea which is an outlier in Figure 4. The bivariate correlation between non-life insurance claims and operating expenses per claim in Figure 5 is -0.48 , strongly significant at little more than $1 \%$. The association between transaction costs and insurance is also quantitatively important. Regressing public social expenditure on a constant and public transaction costs (excluding South Korea) reveals that an increase of public transaction costs by one standard deviation (0.43 percentage points) is associated with 1.4 percentage points less public insurance. Analogously, an increase of private transaction costs by one standard deviation (14.32 percentage points) is associated with 0.35 percentage points less private insurance.

These results remain very similar if we add private transaction costs as a control in the regression for public insurance and public transaction costs as control in the regression for private insurance. Neither of the additional controls is significant in such specifications, a finding that is consistent with our model, where higher transaction costs for private insurance make public transfers more effective in altering consumption levels, but also change the constrained-efficient amounts of transfers.

\section{Concluding comments}

The modeling framework developed in this paper offers distinctive and qualitatively general insights into the implications of private insurance for public insurance policies. In theory, transaction costs in private insurance markets play a crucial role in making it possible for public transfers to affect the consumption allocation, and in shaping the amount and character of constrained-optimal public insurance policies. We show that the extent to which efficient public transfers smooth income 
shocks depends on the trade-off between incentive provision and the dissipation of resources due to wasteful transaction costs. We provide evidence that insurance activities are indeed costly in reality, and we find that available cross-country information on the cost of public and private insurance systems are sensibly and significantly related to their size. Our look at the facts also indicates that a substantial part of private and public insurance variation remains unexplained by transaction costs.

Our framework may be extended in several directions. Various aspects of private insurance organization are potentially relevant to the pricing and information basis of private insurance contracts. Market concentration and information pooling facilities can reduce supply of inefficiently generous private insurance, and are shaped in reality by regulatory and privacy-protection policies. While we have focused on contingent public transfers, the information asymmetries that imply excessive hidden insurance may be addressed by linear taxation of anonymous trades, along the lines of Golosov and Tsyvinski's (2007) analysis of hidden-savings equilibria. Further research could also aim to assess the empirical realism of our model's predictions for the coexistence and interaction of public and private insurance, relative to those of the limited enforcement framework of Krueger and Perri (2009) or of the partial exclusive insurance equilibrium studied by Ales and Maziero (2009).

\section{Appendix}

\section{Part I: Numerical solution of the equilibrium}

For a given number of firms $N$, we iterate over the consumption function $c(z)$.

(i) We start from the no-insurance, no-savings consumption profile $c\left(z_{i}\right)=z_{i}$.

(ii) We then use our parametric assumptions, $f\left(z_{1} \mid e_{1}\right)=\exp \left(-\xi e_{1}\right)$ and equation (3) to find $e_{1}$ which solves

$$
e_{1}-\beta \xi \exp \left(-\xi e_{1}\right) \frac{c\left(z_{2}\right)^{1-\sigma}-c\left(z_{1}\right)^{1-\sigma}}{1-\sigma}=0
$$

(iii) We use the standard Euler equation (7) to compute $c_{1}$ :

$$
c_{1}=\left\{\beta(1+r)\left[\exp \left(-\xi e_{1}\right) c\left(z_{1}\right)^{-\sigma}+\left(1-\exp \left(-\xi e_{1}\right)\right) c\left(z_{2}\right)^{-\sigma}\right]\right\}^{-\frac{1}{\sigma}} .
$$


(iv) We retrieve $q\left(z_{1}\right)$ and $q\left(z_{2}\right)$ using $m(\bar{q}(z) / N)=\exp (\nu \bar{q}(z) / N), \bar{q}(z)=q(z)$ in the symmetric equilibrium, and equations (20) and (21):

$$
\begin{gathered}
q\left(z_{1}\right)=\frac{N}{\nu} \ln \left[\beta(1+r)\left(\frac{c\left(z_{1}\right)}{c_{1}}\right)^{-\sigma}\right], \\
q\left(z_{2}\right)=\frac{N}{\nu} \ln \left[\frac{1-\exp \left(-\xi e_{1}\right) \exp \left(\nu q\left(z_{1}\right) / N\right)}{1-\exp \left(-\xi e_{1}\right)}\right] .
\end{gathered}
$$

(v) We use the budget constraint to update $c(z)$ :

$$
c(z)=z+q(z)+s(z)+\left(y_{1}-c_{1}\right)(1+r)-\sum_{\left\{x \in Y_{2}\right\}} q(x) f\left(x \mid e_{1}\right) \exp (\nu q(x) / N)+X
$$

for $z \in\left\{z_{1}, z_{2}\right\}$, where $X$ as defined in (18) rebates to consumers the operational profits of insurance firms. For the numerical example's exponential functional form,

$$
X=\sum_{\left\{z \in Y_{2}\right\}} f\left(z \mid e_{1}\right)\left[\frac{q(z)}{N} \exp (\nu q(z) / N)-\frac{\exp (\nu q(z) / N)-1}{\nu}\right]
$$

We the restart with step (ii) and iterate until $c(z)$ has converged at precision $10^{-8}$.

It is straightforward to let the number of firms $N$ be determined by a fixed cost $\Xi$ of operation for each insurance firms. Then, in an additional step, a zero-profit condition in the form

$$
\sum_{\left\{z \in Y_{2}\right\}} f\left(z \mid e_{1}\right)\left[\frac{q(z)}{N} \exp (\nu q(z) / N)-\frac{\exp (\nu q(z) / N)-1}{\nu}\right]=\Xi
$$

updates $N$ after $c(z)$ has converged, and we restart with step (ii) until $N$ has converged.

\section{Part II: Data appendix}

We use available OECD data for the time period 1996-2005 in our empirical analysis where not all sample years are available for all variables and some countries such as Mexico and Switzerland are excluded because of missing data. The variables are defined as follows.

Non-old age social expenditure per GDP: Total public social expenditure minus the expenditures in the categories "old age" and "survivors", divided by GDP. Average for the years 1996-2003 
in the OECD Social Expenditure Database. Our measure for public social expenditure includes (i) incapacity-related benefits (care services, disability benefits, benefits accruing from occupational injury and accident legislation, employee sickness payments); (ii) health (in- and out-patient care, medical goods, prevention); (iii) family (child allowances and credits, child care support, income support during leave, sole parent payments); (iv) active labor market policies (employment services, training youth measures subsidized employment, employment measures for the disabled); (v) unemployment (unemployment compensation, severance pay, early retirement for labor market reasons); housing (housing allowances and rent subsidies); and (vi) other social policy areas (noncategorical cash benefits to low-income households, other social services; i.e. support programs such as food subsidies).

Tax administration costs per net revenue collection: Annual costs of administration incurred by a revenue authority divided by the revenue collected over the course of a fiscal year. Average for the years 2000-2002 in OECD (2004), Table 17.

Non-life insurance claims per GDP: Gross claims payments, covering all gross payments on claims made during the financial year, divided by GDP. Median, by country, for the years 19962005 in the OECD Insurance Statistics Yearbook. Non-life insurance includes, among others, insurance in the categories motor vehicle, maritime and aviation, freight, fire and property damages, pecuniary losses, general liability accident and health. Data on claims for the US are not available and imputed using the median of gross non-life insurance premiums multiplied by the average claim-premium ratio for those OECD countries for which data on both premiums and claims are available.

Operating expenses per claim for non-life insurance: Gross operating expenses are the sum of acquisition costs, change in deferred acquisition costs and administrative expenses. These are divided by claims. Median, by country, for the years 1996-2005 in the OECD Insurance Statistics Yearbook. Data for the US are not available and are imputed using the estimate for the loading factor of 1.18 for the long-term care market in Brown and Finkelstein (2007). 


\section{References}

Ábrahám, Árpád and Nicola Pavoni (2005): "The Efficient Allocation of Consumption under Moral Hazard and Hidden Access to the Credit Market," Journal of the European Economic Association, vol. 3, 370-381.

Ábrahám, Árpád, Sebastian Koehne and Nicola Pavoni (2009): "On the First-Order Approach in Principal-Agent Models with Hidden Borrowing and Lending: The First-Order Approach in Two Periods," University College London, working paper.

Ales, Laurence, and Pricila Maziero (2009) "Non-Exclusive Dynamic Contracts, Competition, and the Limits of Insurance," Carnegie Mellon University, working paper.

Bisin, Alberto and Piero Gottardi (1999): "Competitive Equilibria with Asymmetric Information," Journal of Economic Theory, vol. 87, 1-48.

Bizer, David S. and Peter M. DeMarzo (1992): "Sequential Banking," Journal of Political Economy, vol. 100, 41-61.

Brown, Jeffrey R. and Amy Finkelstein (2007): "Why is the Market for Long-Term Care Insurance so small?," Journal of Public Economics, vol. 91, 1967-1991.

Cole, Harold, and Narayana Kocherlakota (2001): "Efficient Allocations with Hidden Income and Hidden Storage," Review of Economic Studies, vol. 68, 523-542.

Golosov, Mikhail, and Aleh Tsyvinski (2007): "Optimal Taxation with Endogenous Insurance Markets," Quarterly Journal of Economics, vol. 122, 487-534.

Gottardi, Piero and Nicola Pavoni (2009): "Ramsey Asset Taxation under Asymmetric Information," University College London, working paper.

Krueger, Dirk and Fabrizio Perri (2009): "Public versus Private Risk Sharing," NBER Working Paper No. 15582.

Mirrlees, James A. (1971): "An Exploration in the Theory of Optimum Income Taxation," Review of Economic Studies, vol. 38, 175-208.

OECD (2004): Tax Administration in OECD Countries: Comparative Information Series, Paris, OECD.

Pauly, Mark V. (1974): "Overinsurance and Public Provision of Insurance: The Roles of Moral Hazard and Adverse Selection," Quarterly Journal of Economics, vol. 88, 44-62.

Rogerson, William P. (1985a): "Repeated Moral Hazard," Econometrica, vol. 53, 69-76. 
Rogerson, William P. (1985b): "The First Order Approach to Principal-Agent Problems," Econometrica, vol. 53, 1357-1368.

Shavell, Steven (1979) "On Moral Hazard and Insurance," Quarterly Journal of Economics, vol. 93, 541-562. 